\title{
APLICAÇÃO DA TEORIA DA MUDANÇA EM UMA ORGANIZAÇÃO DA SOCIEDADE CIVIL
}

\author{
Patrícia Peres Rodrigues iD1 e Cibele Roberta Sugahara iD2 \\ Bruna Angela Branchi ${ }^{3}{ }^{3}$ e Luciel Henrique de Oliveira $\mathrm{D} 4$
}

\section{Resumo}

Na medida em que a sociedade civil abriu espaço para participação nas causas coletivas, as Organizações da Sociedade Civil (OSCs) surgiram com o objetivo de impactar no bem-estar social. A presente pesquisa tem como objetivo apresentar uma proposta de aplicação da Teoria da Mudança para o programa Decola Beta da OSC Cientista Beta. Trata-se de uma pesquisa descritiva e explicativa com abordagem qualitativa. Os procedimentos técnicos usados foram a pesquisa documental e o estudo de caso. Como resultado é apresentado um modelo de aplicação da Teoria da Mudança, que pode contribuir para que os gestores meçam os impactos alcançados pela organização, bem como reúnam dados para apresentação aos investidores, garantindo a sustentabilidade da OSC.

Palavras-chave: Avaliação de impacto; Metodologias de avaliação de programas sociais; Teoria da mudança; Programas sociais.

\section{APPLICATION OF THEORY OF CHANGE IN A CIVIL SOCIETY ORGANIZATION}

\section{Abstract}

As civil society opened space for participation in collective causes, Civil Society Organizations (CSOs) emerged with the aim of impacting social well-being. This research aims to present a proposal for the application of the Theory of Change for the program Decola Beta of the OSC Scientist Beta. It is a descriptive and explanatory research with a qualitative approach. The technical procedures used were documentary research and case study. As a result, an application model of the Theory of Change is presented, which can help managers to measure the impacts achieved by the organization, as well as gather data for presentation to investors, ensuring the sustainability of the CSO.

Keywords: Impact assessment; Evaluation methodologies for social programs; Theory of change; Social programs.

\footnotetext{
${ }^{1}$ Mestre em Sustentabilidade pela Pontifícia Universidade Católica de Campinas (PUC-Campinas).

${ }^{2}$ Doutora em Ciência da Informação Universidade de São Paulo (USP). Professora do Programa de Pós-Graduação em Sustentabilidade e da Faculdade de Administração da Pontifícia Universidade Católica de Campinas.

${ }^{3}$ Doutora em Economia Política Università Degli Studi Di Pavia. Itália. Professora do Programa de Pós-Graduação em

Sustentabilidade e da Faculdade de Ciências Econômicas da Pontifícia Universidade Católica de Campinas.

${ }^{4}$ Doutor em Administração de Empresas pela Fundação Getúlio Vargas - FGV-SP. Professor da Pontifícia Universidade Católica de Minas Gerais (PUCMG) e do Centro Universitário das Faculdade Associadas de Ensino - UNIFAE.
} 


\section{Introdução}

Desigualdade, pobreza e exclusão social caracterizam, em graus diferentes, todas as sociedades. Embora o Estado tenha um papel importante na formulação e adoção de políticas que contribuam para um desenvolvimento abrangente, coerente com o desenvolvimento sustentável e a Agenda 2030 das Nações Unidas, a sua ação pode ser lenta e/ou pouco eficaz (SILVA, 2009). Neste contexto, a sociedade civil tem se mobilizado pressionando o Poder Público e, também, desenvolvendo e implementando ações alternativas que solucionem ou minimizem pobreza e exclusão. Diante desta realidade, a partir da década de 1980, as Organizações Não-Governamentais (ONGs), hoje chamadas de Organizações da Sociedade Civil (OSCs), ganharam importância, assumindo um papel de destaque na sociedade e tornando-se protagonistas na busca de uma melhor condição social para todos.

A questão da avaliação dos programas sociais por parte das OSCs brasileiras se fundamenta no reconhecimento da constante mudança das condições dos programas e dos desafios para atender aos anseios da sociedade.

A avaliação de programas sociais é discutida na literatura, mas existem fatores que dificultam a sua aplicação por parte das organizações. Segundo Assumpção e Campos (2011), a literatura pertinente traz a visão de que quando a avaliação de programas sociais é aplicada restringe-se ao controle dos investimentos financeiros ou serve apenas como relatório de atividades desenvolvidas, não conferindo valor ou mérito à iniciativa.

Diante deste cenário, acredita-se que a forma como as organizações realizam a avaliação de programas sociais pode fragilizar a credibilidade das OSCs, perante as instituições, stakeholders e investidores que possam contribuir de maneira significativa para o programa social.

Este estudo descreve a contribuição da Teoria da Mudança para a avaliação de programas sociais. A partir de um estudo de caso, reforça o entendimento de que a aplicação da Teoria da Mudança, a par dos seus desafios, é possível. O Instituto Cientista Beta foi escolhido para compor o estudo de caso desta pesquisa por ser a única OSC no Brasil que incentiva jovens a desenvolverem a pesquisa científica por meio de projetos estruturados e processo de mentoria, apoiando o desenvolvimento de programas de iniciação científica aos jovens do ensino básico e médio.

A OSC Cientista Beta foi criada em 2015 no estado do Rio Grande do Sul por jovens que sentiram a necessidade de estender o alcance da experiência da pesquisa científica a qualquer estudante do país por meio do estímulo "à criação de projetos científicos centrados em problemas reais e atuais em qualquer área do conhecimento", visando, com isso, causar transformação pessoal e impacto social (CIENTISTA BETA, 2020a, s. p.).

A OSC desenvolve quatro atividades principais: 1) O projeto Decola Beta Professores, que consiste em uma "formação presencial para o trabalho com orientação de projetos científicos desenvolvidos por estudantes de escolas do Ensino Básico"; 2) Organiza e/ou participa de eventos científico-educacionais, 
como feiras e mostras científicas; 3) Disponibiliza uma "coleção de materiais didáticos, composta por conteúdos e atividades-desafio, para Iniciação Científica no Ensino Básico" e 4) Gerencia a plataforma "Mapa das feiras", "que reúne informações sobre feiras de ciências para alunos do Ensino Básico" (CIENTISTA BETA, 2020b, s. p.).

Este trabalho considera que o processo de avaliação de impacto de um programa social a Teoria da Mudança, se alinhada com os objetivos da transformação almejada, pode contribuir com a mensuração do resultado e geração de impacto ao público envolvido. Assim, esta pesquisa teve o objetivo de desenvolver uma proposta de aplicação da Teoria da Mudança para o programa social Decola Beta da Organização Cientista Beta.

\section{Teoria da mudança na avaliação de impacto de programas sociais}

A literatura aponta que as metodologias de avaliação de impacto de programas sociais oferecem às OSCs uma forma de comunicar seu resultado, reforçar sua legitimidade na sociedade e aumentar sua atratividade perante investidores sociais (BENGO et al., 2016; MURAD, 2017; GASPARINI; FURTADO, 2014). Sendo assim, entende-se que a forma como as organizações realizam a avaliação de programas sociais pode fragilizar a credibilidade das OSCs, que têm dificuldade em relatar seus avanços.

Bengo et al. (2016) pontuam que a falta de indicadores e métricas de avaliação de impacto confiáveis limitam a capacidade das organizações sociais de competir no cenário socioeconômico por três razões: 1) diminui a capacidade das organizações sociais de atraírem recursos por meio de investimentos e doações, uma vez que os potenciais investidores/doadores não possuem instrumentos confiáveis e reconhecidos para avaliar o potencial e os resultados de seus investimentos e compará-los com outras opções de investimento; 2) limita a possibilidade de obterem o apoio dos formuladores de políticas; 3 ) enfraquece a capacidade dos próprios gerentes de planejar e controlar suas atividades operacionais e de se comunicar com a ampla gama de stakeholders.

Quanto ao acesso dos gestores a informações sobre metodologias de avaliação de impacto de programas sociais, Assumpção e Campos (2011) alertam para a falta de estudos acadêmicos que demostrem o acompanhamento e análise de programas sociais e que possibilitem que as instituições demonstrem o retorno social das intervenções. Além disso, os autores citam a ausência de materiais que auxiliem, de forma didática, os atores sociais a avaliarem as intervenções além dos aspectos da economia, eficiência e eficácia.

Mayne (2015) afirma que a Teoria da Mudança tem uma ampla gama de usos possíveis no desenvolvimento, gerenciamento e avaliação de intervenções. A Teoria da Mudança possibilita trabalhar com "atributos para avaliação, mensuração e acompanhamento do impacto alinhado ao contexto específico da comunidade, população ou território objeto da intervenção" (SUGAHARA; RODRIGUES, 2019). A construção da Teoria da Mudança contribui com a identificação das lacunas na lógica do projeto e com o levantamento de 
resultados e impactos, como afirmam Fabiani et al. (2018). Nesse sentido, Chen (2012) ainda acrescenta que o objetivo da avaliação orientada pela Teoria da Mudança não é apenas avaliar se uma intervenção funciona ou não, mas também como e por que isso acontece.

A Teoria da Mudança além de permitir avaliar os impactos de um programa, considera também como esses impactos foram criados e quais fatores foram responsáveis pelo sucesso ou fracasso do programa. À medida que se reconhece a Teoria da Mudança como uma ferramenta a serviço da avaliação e não propriamente uma metodologia de avaliação de impacto contribui-se para a realização do mapeamento dos elementos do processo de mudança (WILLIAMS, 2009).

Muito se fala a respeito do processo de desenvolvimento da Teoria da Mudança a partir de uma abordagem de mapeamento que começa com a descrição do que se pretende alcançar a longo prazo e, em seguida, são mapeados o processo de mudança e os resultados de curto e médio prazo necessários para alcançar esse objetivo (BREUER et al., 2016; LIMEIRA, 2018; RIBEIRO, 2017).

Embora a literatura apresente nomes distintos, os elementos da Teoria da Mudança são os insumos ou inputs são os recursos aplicados no empreendimento. As atividades ou activities são as principais ações. As saídas ou outputs são os resultados passíveis de mensuração. Os resultados ou outcomes ou impactos são as modificações nos sistemas sociais. Os alinhamentos dos objetivos referem-se às atividades e ajustes de metas. (OLSEN; GALIMIDI, 2008).

\section{Metodologia}

Trata-se de uma pesquisa descritiva e explicativa com abordagem qualitativa. Os procedimentos técnicos utilizados foram a pesquisa documental e o estudo de caso.

Para a coleta de dados foi realizada uma entrevista semiestruturada com uma gestora/mentora do Programa Decola Beta da Cientista Beta, em janeiro de 2020. Foram abordadas perguntas como: Quais ações e/ou programas a OSC desenvolve para atender a sua missão? Como são medidos os impactos das atividades? Quais metodologias de avaliação de impacto a Sra. Conhece? Como a instituição analisa se os impactos da intervenção do Programa Decola Beta estão alinhados com a missão da iniciativa? Quais indicadores de impacto a ONG utiliza? Vale destacar que a pesquisa teve a aprovação do Conselho de Ética e Pesquisa da Universidade.

Para complementar a coleta de dados, recorreu-se à consulta de informações disponibilizadas no site da OSC, nas seções: (a) Programa de Ensino de Iniciação Científica Decola Beta Professores, (b) Programa de Iniciação Científica Decola Beta Estudantes, (c) Experiência Beta, e (d) e-book Decola Beta 2019. 
Quanto a delimitação do objeto, o estudo de caso escolhido é o instituto educacional sem fins lucrativos Cientista Beta que atua na área de educação. Para a análise dos dados do estudo, foi adotado o modelo lógico que permite separar as diferentes fases de avaliação de um programa social por meio de seus elementos (insumos, atividades, resultados, mudanças e impactos) considerando os fundamentos de Cruz Filho (2018).

\section{Resultados e discussões}

A proposta de aplicação da Teoria da Mudança foi elaborada com base no modelo de Cruz Filho (2018), a partir das etapas do processo de avaliação de impacto. Este modelo baseado na Teoria da Mudança objetiva guiar os membros da OSC no gerenciamento e avaliação de seus projetos atuais e futuros, auxiliando-os a identificar os impactos da intervenção.

O modelo é apresentado na Figura 1. Em seguida, são descritas as etapas envolvidas no processo de avaliação de impacto.

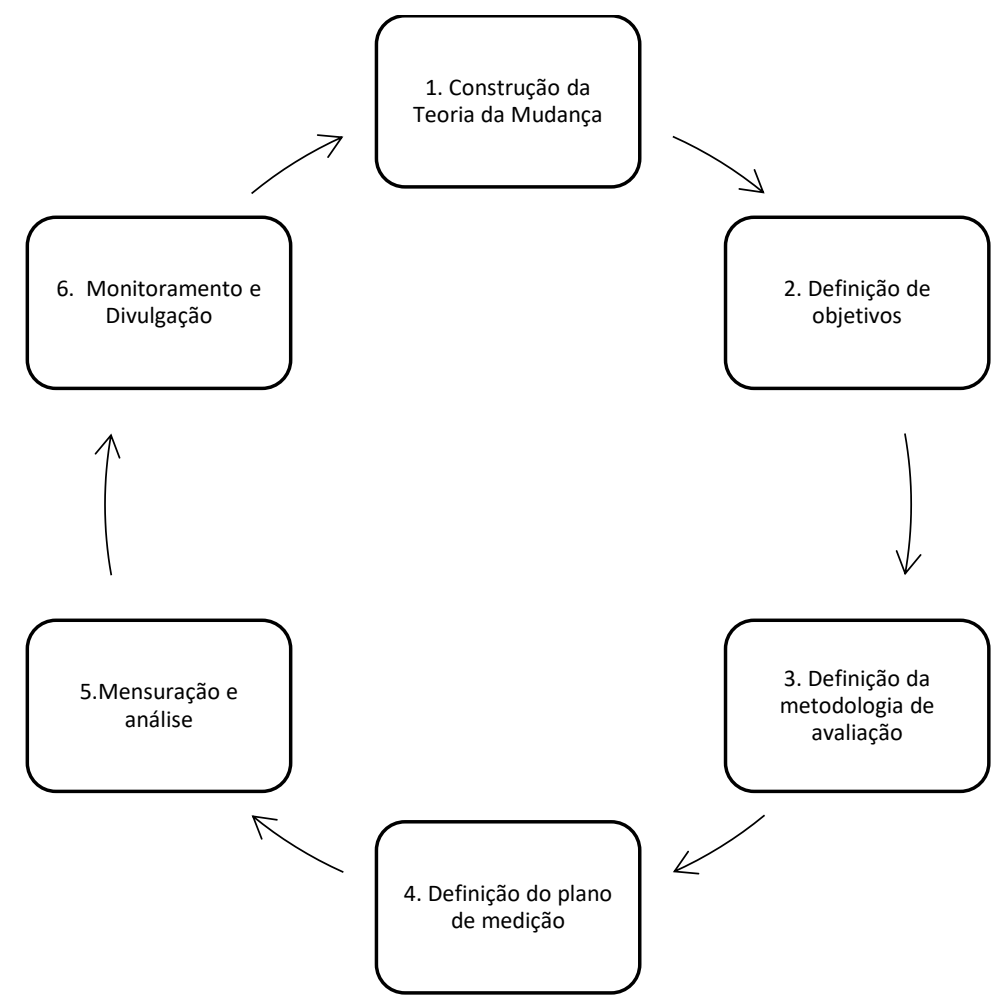

Figura 1: Modelo de avaliação de impacto de programas sociais baseado na Teoria da Mudança Fonte: Elaborado pelos autores a partir de Cruz Filho (2018).

\section{Etapa 1 - Construção da Teoria da Mudança}

De acordo com Cruz Filho (2018) a primeira etapa de uma avaliação de impacto baseia- se em responder à pergunta: "o que é o meu impacto?". Sem essa definição, toda a dedicação para se avaliar o empenho será em vão, pois podem ser realizadas iniciativas desconexas e sem alinhamento. Portanto, é preciso primeiramente realizar um descritivo da finalidade e atuação da (1)(1) 
iniciativa, respondendo às questões: 1) Por que/para que a ONG Cientista Beta existe? Qual mudança/transformação a organização quer causar? (missão organizacional); 2) Quais os programas e atividades que a ONG realiza para atingir a missão (escopo de atuação); 3) Qual é o alcance de tais programas nos âmbitos local, regional, nacional ou global? (escala da operação).

O Quadro 1 apresenta uma proposta para a descrição da finalidade da OSC cientista Beta.

Quadro 1 - Descrição da finalidade da OSC Cientista Beta
\begin{tabular}{|l|l|}
\hline $\begin{array}{l}\text { Missão } \\
\text { organizacional }\end{array}$ & $\begin{array}{l}\text { Despertar a curiosidade e o potencial de estudantes e de seus professores, } \\
\text { utilizando o método científico para estimular a criação de projetos científicos } \\
\text { centrados em problemas reais e atuais, em qualquer área do conhecimento. } \\
\text { Assim, contribuir para a formação de pensamento crítico e para o } \\
\text { desenvolvimento de habilidades e competências essenciais para a sociedade } \\
\text { do século XXI. }\end{array}$ \\
\hline $\begin{array}{l}\text { Escopo } \\
\text { operacional }\end{array}$ & $\begin{array}{l}\text { Formação presencial para o trabalho com orientação de projetos científicos } \\
\text { desenvolvidos por estudantes de escolas do Ensino Básico. } \\
\text { Disponibilização de coleção de materiais didáticos, composta por conteúdos } \\
\text { e atividades-desafio, para Iniciação Científica no Ensino Básico. } \\
\text { Organização e/ou participação em eventos científico-educacionais. Feiras e } \\
\text { mostras científicas, atividades escolares, iniciativas de divulgação científica } \\
\text { etc. } \\
\text { Plataforma que reúne informações sobre feiras de ciências para alunos do } \\
\text { Ensino Básico. }\end{array}$ \\
\hline Escala & $\begin{array}{l}\text { Com o uso da tecnologia, as iniciativas podem ser acessadas por } \\
\text { comunidades escolares de todo o Brasil. }\end{array}$ \\
\hline
\end{tabular}

Fonte: Elaborado pelos autores a partir de Cientista Beta 2020b.

Para Cruz Filho (2018), o segundo momento da etapa 1 consiste em uma análise da dimensão do impacto que a iniciativa vai gerar na vida das pessoas, de maneira que seja possível mensurá-lo. Este é uma das funções da Teoria da Mudança, que pode servir como um guia para a OSC alcançar a mudança necessária. Conforme já apresentado anteriormente nesta pesquisa, a estrutura da Teoria da Mudança é formada por cinco elementos: recursos, atividades, produtos, resultados e impacto. Desta forma, apresenta-se no Quadro 2 uma proposta de Teoria da Mudança para a OSC Cientista Beta, com base nas informações coletadas na entrevista e no site da instituição.

\section{Quadro 2 - Proposta de Teoria da Mudança para a OSC Cientista Beta}

\begin{tabular}{|l|l|}
\hline Recursos & $\begin{array}{l}\text { Os recursos humanos da OSC Cientista Beta correspondem a três } \\
\text { colaboradores e a mentores voluntários. Os recursos financeiros são } \\
\text { provenientes de doações de campanhas de financiamento coletivo. }\end{array}$ \\
\hline Atividades & $\begin{array}{l}\text { Decola Beta Professores - Formação presencial para o trabalho com orientação } \\
\text { de projetos científicos desenvolvidos por estudantes de escolas do Ensino } \\
\text { Básico. } \\
\text { Coleção Decola Beta - Coleção de materiais didáticos, composta por conteúdos } \\
\text { e atividades-desafio, para Iniciação Científica no Ensino Básico. }\end{array}$ \\
\hline
\end{tabular}




\begin{tabular}{|l|l|}
\hline & $\begin{array}{l}\text { Eventos de Ciência e Educação: Organização e/ou participação em eventos } \\
\text { científico-educacionais. Feiras e mostras científicas, atividades escolares, } \\
\text { iniciativas de divulgação científica, etc. } \\
\text { Mapa das Feiras - Plataforma que reúne informações sobre feiras de ciências } \\
\text { para alunos do Ensino Básico. }\end{array}$ \\
\hline Produtos & $\begin{array}{l}\text { Mais de 150 professores de escolas públicas e privadas, em diversos estados } \\
\text { do Brasil, foram formados pelo Programa Decola Beta Professores. O programa } \\
\text { foi desenvolvido com base na experiência com a orientação e mentoria de } \\
\text { projetos científicos de mais de } 450 \text { estudantes do ensino básico nos últimos } \\
\text { quatro anos. }\end{array}$ \\
\hline Resultados & $\begin{array}{l}\text { Elaboração de projetos científicos centrados em problemas reais e atuais em } \\
\text { diversas áreas do conhecimento. }\end{array}$ \\
\hline Impacto & $\begin{array}{l}\text { Propiciar mudanças na vida dos participantes, para que passem a acreditar na } \\
\text { ciência como ferramenta de transformação social e pessoal e como construção } \\
\text { do conhecimento. }\end{array}$ \\
\hline
\end{tabular}

Fonte: Elaborado pelos autores a partir de Cientista Beta 2020b.

\section{Etapa 2 - Definição de objetivos da avaliação}

A elaboração da Teoria da Mudança permite que os Gestores das OSCs tenham uma noção clara dos resultados e impactos gerados por suas atividades. Após o entendimento destes pontos, deve-se compreender plenamente quais os objetivos da avaliação de impacto. Para isso, a OSC deve responder a três perguntas: 1) Por que avaliar e mensurar o impacto?; 2) Para quem o impacto estará sendo avaliado?; 3) O que deve ser avaliado? (CRUZ FILHO, 2018). Os motivos pelo qual realizar a avaliação de impacto e para quem esta avaliação deve ser feita devem estar muito claros para os gestores das OSCs antes do início do processo de avaliação.

Cruz Filho (2018) aponta três motivos pelos quais as OSCs devem avaliar o impacto dos seus programas ou ações: 1 ) subsidiar a prestação de contas; (2) adotar a avaliação como instrumento de gestão e (3) aproveitá-la como avaliação de desempenho. Como proposta de ações, aconselha-se que a OSC Cientista Beta avalie seu impacto para prover prestação de contas aos doadores, investidores, parceiros, poder público (editais), sociedade, professores, estudantes e cidadãos sobre como são aplicados os recursos obtidos e quais os "resultados" obtidos. Quanto ao uso da avaliação de impacto como ferramenta de gestão, sugere-se que ela auxilie os colaboradores da OSC na tomada de decisões estratégicas. E, por fim, como avaliação de desempenho da performance dos programas, esta deve ser uma ferramenta para melhoria dos serviços prestados aos jovens participantes e para a sociedade.

De maneira igualmente importante, Cruz Filho (2018) ressalta que é preciso que a OSC tenha ciência da informação a ser levantada no processo de avaliação. Neste momento, é importante que a OSC revisite a sua Teoria da Mudança para apontar qual a abrangência do processo de avaliação. No caso da OSC Cientista Beta, considerando que a organização está iniciando o seu processo de avaliação de impacto e já mede os "produtos" de suas atividades, o indicado é que, em um primeiro ciclo de avaliação, se inicie a medição dos 
"resultados". Posteriormente, com maior maturidade do processo, deve-se medir os impactos alcançados.

\section{Etapa 3 - Definição da metodologia de avaliação}

O processo de avaliação de impacto tem continuidade com a definição da metodologia de avaliação de impacto que será utilizada. De acordo com Cruz Filho (2018), duas ações são primordiais nessa etapa: (1) a definição inicial dos indicadores e (2) a definição da metodologia de avaliação.

\section{Definição inicial dos indicadores}

Cruz Filho (2018) esclarece que a definição inicial dos indicadores é a continuidade da reflexão iniciada no final da etapa anterior. No caso da OSC Cientista Beta, por exemplo, é possível identificar nos materiais disponibilizados no site e a partir da entrevista que os indicadores de produto são a quantidade de professores treinados e de estudantes que passaram pelo programa de mentoria. Assim, no Quadro 3 sugerem-se novos indicadores de produtos, de resultados e de impactos para auxiliar no processo de avaliação de impacto do Programa Decola Beta.

\begin{tabular}{|c|c|}
\hline $\begin{array}{l}\text { Indicadores } \\
\text { de produtos }\end{array}$ & $\begin{array}{l}\text { Pode-se incluir a quantidade de downloads dos materiais da coleção Decola } \\
\text { Beta, a quantidade de feiras divulgadas e a quantidade de organização } \\
\text { e/ou participação em eventos científico-educacionais }\end{array}$ \\
\hline $\begin{array}{l}\text { Indicadores } \\
\text { de resultados }\end{array}$ & $\begin{array}{l}\text { Pode-se considerar indicadores quantitativos, tal como a quantidade de } \\
\text { projetos científicos desenvolvidos, de artigos científicos escritos por } \\
\text { estudantes, de painéis apresentados por estudantes, etc. }\end{array}$ \\
\hline $\begin{array}{l}\text { Indicadores } \\
\text { de impacto }\end{array}$ & $\begin{array}{l}\text { Podem-se usar indicadores qualitativos, como histórias dos egressos } \\
\text { atingidos pela iniciativa, expondo a sua realidade antes e após a } \\
\text { intervenção e o que teria acontecido se não tivessem participado. } \\
\text { Indicadores quantitativos também podem ser obtidos por meio de } \\
\text { questionários enviados aos egressos durante alguns anos após sua saída } \\
\text { do programa, para comprovação de que a intervenção causou } \\
\text { transformações duradouras na vida dos participantes e para se saber } \\
\text { quantos continuaram a estudar, quantos abandonaram, quantos } \\
\text { ingressaram na graduação e quantos se formaram. Com estas } \\
\text { informações, poderiam ser calculadas a taxa de evasão escolar, a taxa de } \\
\text { ingresso na graduação e a proporção dos egressos do programa Decola } \\
\text { Beta que se formaram. Estes resultados, comparados com as } \\
\text { correspondentes taxas médias da unidade da federação ou do Brasil, } \\
\text { permitiriam ter uma avaliação do impacto do programa Decola Beta. }\end{array}$ \\
\hline
\end{tabular}

Fonte: Elaborado pelos autores.

Com relação aos egressos de programas sociais, Birman (2016) alerta que os organizadores de programas sociais deveriam priorizar o conhecimento das mudanças que ocorrem na vida dos jovens após o término de sua participação nestes programas, como forma de avaliar o impacto das intervenções. Em consonância com este pensamento, Murad (2017) destaca em seu estudo que o 
papel das OSCs não deve ser apenas tratar de problemas atuais, mas realizar ações que tragam mudanças e alcancem resultados significativos.

\section{Escolha da metodologia de avaliação}

Em relação à escolha da metodologia de avaliação de impacto, Cruz Filho (2018) apresenta níveis de complexidade de metodologias, iniciando pelo primeiro nível, que consiste na descrição da realidade antes e após a intervenção. Neste caso, mede-se a situação anterior à avaliação, a evolução durante a intervenção e, ao final, compara-se os resultados.

Em linha com esta ideia, para avaliação do programa Decola Beta, a OSC aplica uma metodologia própria que consiste no preenchimento de um questionário intitulado raio-x inicial pelo aluno, pelo mentor e pelo mentor parceiro quando estes entram no programa. Depois que o programa se encerra, estes participantes respondem a outro questionário, chamado raio-x final, e um questionário de feedback do programa, todos anônimos. Ao longo do programa, a OSC acompanha alguns índices, como a taxa de abertura da Newsletter semanal enviada por e-mail, a taxa de evasão do programa e o número de desafios entregues no ano pelos estudantes. Sugere-se incluir também a quantidade de artigos científicos produzidos durante o programa.

O nível de metodologias mais avançado descrito por Cruz Filho (2018) são as que contemplam a monetização dos resultados, transformando o impacto medido em valor monetário. Uma das metodologias que permitem esta monetização é a Social Return of Investment (SROI), principalmente no caso do direcionamento da avaliação para os financiadores. O SROI objetiva medir o valor dos benefícios sociais criados por uma organização em relação ao custo da intervenção (BENGO et al., 2016; BRANDÃo et al., 2014). A metodologia "pode ser usada como uma ferramenta para planejamento e aprimoramento estratégico, para comunicar impacto e atrair investimento ou para tomar decisões de investimento" (IDIS; CAF, 2012, p. 10). Nesta metodologia, os indicadores avaliados são relacionados com parâmetros que possibilitam definir um valor monetário a eles. "O grande desafio é comparar o valor monetário investido com o valor social gerado, devido à dificuldade de tal valor social ser transformado em unidades monetárias" (PAULA; BRASIL; MÁRIO, 2009, p. 136). Porém, considerando a OSC Cientista Beta, os programas oferecidos aos estudantes e professores gratuitamente podem ser monetizados pelo valor equivalente ao de programas similares realizados por uma instituição privada, tendo-se assim o valor monetário da iniciativa. O SROI, pela sua natureza não experimental, necessita estar "fortemente ancorado em uma Teoria de Mudança bem estruturada" (FABIANI et al., 2018, p. 12), o que confirma a importância da construção da Teoria da Mudança para a escolha da metodologia de avaliação.

O IDIS (2020) reconhece a importância do SROI na avaliação de programas sociais como um método para medir o valor social não refletido nas contas financeiras convencionais e como uma maneira de melhorar o desempenho dos programas. Em vista disso, o instituto relata que está conduzindo avaliações de impacto utilizando a metodologia SROI para três 
organizações sociais conhecidas nacionalmente pela relevância de seus projetos, a Amigos do Bem, a Gerando Falcões e a Parceiros da Educação (IDIS, 2020).

Outras sugestões de metodologias de avaliação de impacto para o Programa Decola Beta seriam a comparação de grupos utilizando o método quase experimental. Nesse sentido, a metodologia Difference in Differences (DID), apresenta em seu escopo atributos aderentes ao propósito do Programa Decola Beta. A metodologia Difference in Differences objetiva comparar o grupo de tratamento com um grupo semelhante que existe em outro lugar e que não é criado por meio de randomização, uma técnica que contribui para que as características da amostra sejam homogêneas (VELDMAN, 2009). A aplicação da metodologia quase-experimental deve ser concomitante com o começo do programa. A partir do conhecimento das características socioeconômicas e demográficas do grupo participante, poderia ser selecionado um grupo, com características parecidas, que não participa e que teria o papel de benchmark. O grupo de comparação possibilitaria medir as mudanças que o programa está gerando no grupo participante. Um ponto a se destacar sobre o uso desta metodologia é o custo para criação e acompanhamento do grupo de comparação.

É relevante destacar, como mencionado por Assumpção e Campos (2011, p. 210), "que os modelos avaliativos podem ser influenciados pela natureza de atuação, por crenças filosóficas e ideológicas e predileções metodológicas dos gestores das OSCs", portanto deve-se tomar cuidado para que esta tendência não influencie negativamente na escolha da metodologia de avaliação. Assim, em decorrência da natureza do foco de atuação que a OSC Cientista Beta atua, sugere-se a adoção de avaliações que subsidiem as atividades desenvolvidas com os participantes do programa e a gestão, a fim de estabelecer um processo contínuo de aperfeiçoamento do programa Decola Beta.

\section{Definição do plano de medição}

Após o cumprimento das etapas anteriores, é necessário definir um plano de medição de impacto. O plano visa medir a situação antes da intervenção, reforçar a atribuição e a causalidade, avaliar o que será feito com os dados obtidos e processar o aprendizado ao longo do processo. Os elementos essenciais para a elaboração do plano de medição são: hipóteses (por indicador), métricas (por indicador), cronograma, responsável, amostragem, fontes e instrumentos de coleta, instrumento de registro, custo, riscos e estratégias (CRUZ FILHO, 2018). Entretanto, dependendo da metodologia de avaliação de impacto escolhida, esses elementos podem ser alterados (CRUZ FILHO, 2018). O Quadro 4 apresenta orientações para elaboração do plano de medição pela OSC Cientista Beta. 


\begin{tabular}{|c|c|}
\hline $\begin{array}{l}\text { Hipótese (por } \\
\text { indicador) }\end{array}$ & $\begin{array}{l}\text { Para cada indicador determinado nas etapas da Teoria da Mudança, elaborar } \\
\text { uma hipótese de resultado com um prazo para realização. Por exemplo: Se o } \\
\text { programa Decola Beta Professores for divulgado em escolas particulares de } \\
\text { certo estado, o número de participantes deverá aumentar X\% em um ano. }\end{array}$ \\
\hline $\begin{array}{l}\text { Métricas (por } \\
\text { indicador) }\end{array}$ & $\begin{array}{l}\text { Para cada indicador determinado, estabelecer uma métrica específica, que } \\
\text { pode ser em: quantidade, porcentagem, valor, tempo, percepção, etc. Tal } \\
\text { como, em um ano, o número de professores treinados, o número de } \\
\text { estudantes que participam do programa de mentoria, o número de downloads } \\
\text { dos materiais da coleção Decola Beta, a porcentagem dos professores que } \\
\text { declaram que melhoraram suas aulas após a participação no programa, } \\
\text { dentre outros. }\end{array}$ \\
\hline Cronograma & $\begin{array}{l}\text { De acordo com informações coletadas na entrevista, os gestores da OSC } \\
\text { Cientista Beta fazem uma imersão da equipe em um fim de semana no início } \\
\text { de cada ano. Nesta oportunidade, pode ser elaborado um cronograma da } \\
\text { avaliação de impacto, englobando cada uma das seis etapas do processo de } \\
\text { mensuração de impacto para o período de um ano. }\end{array}$ \\
\hline Responsável & $\begin{array}{l}\text { Determinar quem da equipe da OSC Cientista Beta será o gestor do processo } \\
\text { de mensuração de impacto e quem serão os responsáveis em cada uma das } \\
\text { etapas do cronograma. Aconselha-se que o ocupante do mais alto nível de } \\
\text { gestão seja o líder do processo de mensuração de impacto, devido à } \\
\text { importância deste processo. }\end{array}$ \\
\hline Amostragem & $\begin{array}{l}\text { Definir quais serão as pessoas ou elementos avaliados. No caso da OSC } \\
\text { Cientista Beta, seriam os estudantes, professores, downloads de material e } \\
\text { acessos ao site. } \\
\text { Determinar o tamanho da amostra para os indicadores qualitativos. Sugere- } \\
\text { se obter o relato de ao menos cinco professores e de dez estudantes, para } \\
\text { depoimento sobre o impacto da intervenção em sua vida. }\end{array}$ \\
\hline $\begin{array}{l}\text { Fontes e } \\
\text { instrumentos } \\
\text { de coleta }\end{array}$ & $\begin{array}{l}\text { Estabelecer de onde os dados dos indicadores serão extraídos e quais serão } \\
\text { os instrumentos de coleta. Por exemplo: formulários de inscrição, entrevistas } \\
\text { e coletas de histórias. }\end{array}$ \\
\hline $\begin{array}{l}\text { Instrumento } \\
\text { de registro }\end{array}$ & $\begin{array}{l}\text { Definir como o processo e os dados coletados serão registrados e } \\
\text { armazenados para futuras consultas e avaliações, bem como os } \\
\text { procedimento de backup dos dados e senhas de acesso. Recomenda-se que } \\
\text { todos os arquivos digitais sejam organizados em pastas e salvos no } \\
\text { computador do responsável pelo processo de avaliação de impacto. Pode-se } \\
\text { criar um backup ao salvar os arquivos também em pendrive. Orienta-se que } \\
\text { sejam mantidos os arquivos por no mínimo cinco anos. }\end{array}$ \\
\hline Custo & $\begin{array}{l}\text { Levantar o custo de todo o processo de avaliação, englobando o tempo da } \\
\text { equipe, materiais utilizados, contratação de serviços, etc. }\end{array}$ \\
\hline $\begin{array}{l}\text { Riscos e } \\
\text { estratégias }\end{array}$ & $\begin{array}{l}\text { Relacionar os riscos intrínsecos ao processo e o plano de ação caso problemas } \\
\text { aconteçam. Os riscos que podem ser identificados no processo de } \\
\text { mensuração de impacto são a perda dos dados coletados ou a recusa dos } \\
\text { participantes em responder aos questionários ou em relatar suas histórias. } \\
\text { Para evitar a perda dos dados, recomenda-se fazer um backup dos arquivos } \\
\text { gerados. Já para prevenir a pouca quantidade de dados, recomenda-se enviar } \\
\text { o máximo possível de questionários e coletar o maior número de } \\
\text { depoimentos, para não comprometer o processo de coleta de dados para os } \\
\text { indicadores. }\end{array}$ \\
\hline
\end{tabular}

Fonte: Elaborado pelos autores a partir de Cruz Filho (2018).

\section{Etapa 5 - Mensuração e análise}

A quinta etapa do processo de avaliação de impacto é dividida em duas fases. A primeira é a aplicação do plano de medição formulado, seguindo todas 
as quatro etapas descritas anteriormente. Desta forma, será realizada a mensuração do impacto ambiental.

A próxima fase é uma reflexão sobre o que foi observado no processo de mensuração do impacto. Nesta fase é importante que a OSC Cientista Beta identifique se o impacto do programa atendeu aos objetivos iniciais da avaliação, determinados na etapa 2 da avaliação, e se estão de acordo com a missão da OSC, identificados na etapa 1 da avaliação. Depois, segundo Cruz Filho (2018, p. 238), "verificam-se as questões de atribuição e causalidade e se o custo do programa foi compatível com o impacto obtido", conforme a etapa 4, além de avaliar quanto tempo o impacto realizado durará (etapa 3). Esta análise pode ser feita durante a coleta dos dados ou após a mensuração. E, por fim, determina-se se os resultados estão apropriados para divulgação (CRUZ FILHO, 2018). A figura 2 ilustra este fluxo de mensuração e análise.

Figura 2 - Fluxo de mensuração e análise na avaliação de impacto de programas sociais.

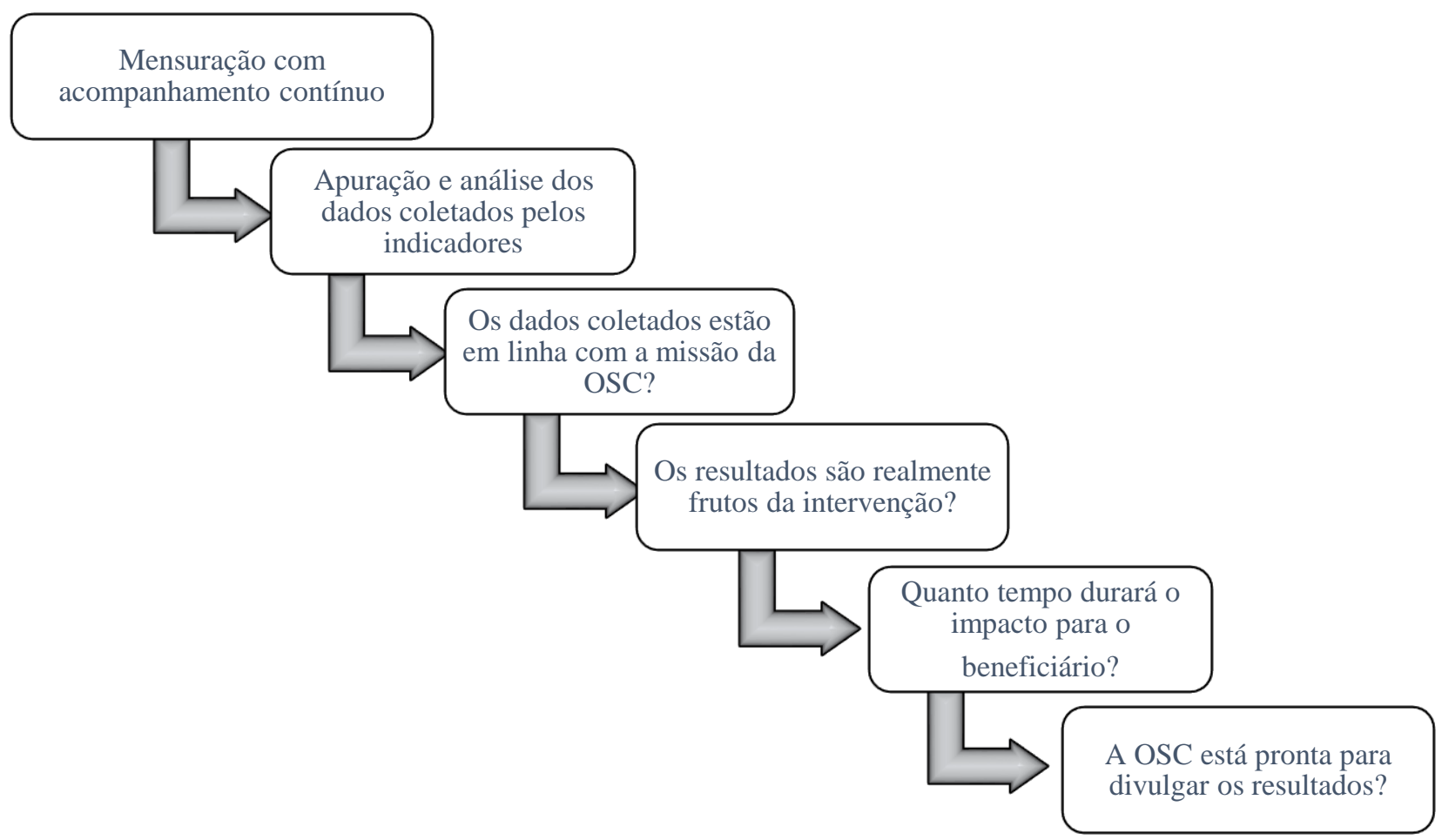

Fonte: Elaborado pelos autores com base em Cruz Filho (2018).

\section{Etapa 6 - Monitoramento e divulgação}

Cruz Filho (2018) explica que a última etapa da avaliação de impacto abrange 0 monitoramento de todo o processo e de sua continuidade, pois quando um ciclo de avaliação termina, outro deve ser iniciado na sequência, a partir da primeira etapa. Os aprendizados precisam ser avaliados e considerados nas seis etapas do novo ciclo que se iniciará. 
Além do mais, nesta etapa prepara-se a divulgação do impacto aferido, caso seja de interesse da organização. Recomenda-se que o impacto mensurado pela OSC Cientista Beta seja divulgado nos e-books, também chamados de Relatórios de Impacto, disponibilizados no site da instituição.

$\mathrm{Na}$ divulgação, uma maneira de favorecer a compreensão sobre a importância do impacto mensurado é a aproximação dos principais impactos às metas dos Objetivos de Desenvolvimento Sustentável (ODS) da ONU (CRUZ FILHO, 2018). Os 17 ODS e as respectivas 169 metas são detalhados na Agenda 2030 adotada durante a Cúpula das Nações Unidas sobre o Desenvolvimento Sustentável em setembro de 2015. No caso da OSC Cientista Beta, pode-se perceber a relação entre os impactos do programa com algumas metas do ODS 4 - Educação de Qualidade, conforme Quadro 5.

\section{Quadro 5 - Atendimento de metas do ODS 4 pelo Programa Decola Beta}

Descrição das metas do ODS 4
4.4 Até 2030, aumentar substancialmente
o número de jovens e adultos que tenham
habilidades relevantes, inclusive
competências técnicas e profissionais para
emprego, trabalho decente e
empreendedorismo.

4.5 Até 2030, eliminar as disparidades de gênero na educação e garantir a igualdade de acesso a todos os níveis de educação e formação profissional para os mais vulneráveis, incluindo as pessoas com deficiência, povos indígenas e as crianças em situação de vulnerabilidade.

4.c Até 2030, substancialmente aumentar o contingente de professores qualificados, inclusive por meio da cooperação internacional para a formação de professores, nos países em desenvolvimento, especialmente os países menos desenvolvidos e pequenos Estados insulares em desenvolvimento.

Fonte: Elaborado pelos autores.

Os resultados refletem que o Programa Decola Beta da OSC Cientista Beta contribui para o atendimento do Objetivo do Desenvolvimento Sustentável no 4 da Agenda 2030 da ONU - Educação de Qualidade - "Assegurar a educação inclusiva e equitativa e de qualidade, e promover oportunidades de aprendizagem ao longo da vida para todas e todos", principalmente no que tange à meta 4.4 "aumentar substancialmente o número de jovens e adultos que tenham habilidades relevantes, inclusive competências técnicas e profissionais, para emprego, trabalho decente e empreendedorismo" (NAÇÕES UNIDAS BRASIL, 2020, s. p.). Isso porque gera benefícios diretos aos estudantes e professores participantes e ao mesmo tempo para a sociedade. 


\section{Considerações finais}

A Teoria da Mudança é uma ferramenta que possibilita qualificar os programas sociais na medida em que requer um planejamento dos seus elementos constituintes. É fundamental o desenvolvimento de novos estudos que demonstrem a aplicação da ferramenta da Teoria da Mudança como etapa que antecede o uso de metodologia de avaliação de impacto e auxiliando na escolha da melhor metodologia para avaliação do programa.

O trabalho apresenta uma proposta de aplicação da Teoria da Mudança para o programa social Decola Beta. A OSC Cientista Beta valoriza a ciência, portanto, com a construção da Teoria da Mudança tem a disposição um instrumento para avaliar e monitorar os resultados obtidos pelo Programa Decola Beta utilizando indicadores. Logo, essa ferramenta facilita a ação da OSC no sentido de propiciar mais informações aos stakeholders sobre os impactos de longo prazo do programa, possibilitando "aos gestores obterem dados necessários para poder captar recursos por meio da celebração de parcerias, atração de investimentos e participação em editais de fomento" (MURAD, 2017, p. 93).

É essencial que a OSC Cientista Beta, apesar de suas limitações de infraestrutura e de recursos humanos, aceite o desafio de se dedicar à aplicação desta ferramenta científica, para que possa realizar uma avaliação de impacto que propicie uma reflexão mais crítica sobre a efetividade do programa Decola Beta, mostrando como ele pode ser trabalhado para que aumente o impacto almejado e realmente traga mudanças positivas e duradouras aos seus participantes.

Além de aplicar a ferramenta Teoria da Mudança às necessidades da OSC Cientista Beta, também se espera que o estudo possa servir de modelo e agregar conhecimento a outras OSCs e Negócios Sociais que buscam uma ferramenta para avaliação de seus programas.

Considerando a importância dos impactos gerados pelo Programa Decola Beta à sociedade, recomenda-se que na aplicação da proposta da Teoria da Mudança esse modelo seja visto como um processo cíclico e contínuo, que requer adequações ao longo do tempo. A partir dos resultados desta pesquisa, acreditase que a ferramenta Teoria da Mudança permitirá à OSC Cientista Beta explicitar e comparar as mudanças geradas antes e depois da aplicação da Teoria da Mudança numa perspectiva de longo prazo.

\section{REFERÊNCIAS}

ASSUMPÇÃO, Jairo José; CAMPOS, Lucila Maria de Souza. Avaliação de projetos sociais em ONGs da Grande Florianópolis: um estudo sobre modelos relacionados ao foco de atuação. Revista de Administração Pública. v. 45, n. 1, p. 209-242, 2011. 
BENGO, Irene; ARENA, Marika; CALDERIN, Mario. Indicators and metrics for social business: a review of current approaches. Journal of Social Entrepreneurship, v. 7, n. 1, p. 1-24, 2016.

BIRMAN, Eliane. Avaliação de egressos de projetos sociais: o que sabemos sobre o pós-projeto? 2016. Dissertação. (Mestrado em Engenharia de Produção) - Instituto Alberto Luiz Coimbra de Pós-Graduação e Pesquisa de Engenharia (Coppe) da Universidade Federal do Rio de Janeiro, Rio de Janeiro, 2013.

BRANDÃO, Daniel; CRUZ, Célia; ARIDA, Anna Livia. Métricas em Negócios de Impacto Social: Fundamentos. São Paulo: ICE/MOVE, 2014.

BREUER, Erica; LUCY LEE, Mary de Silva; LUND, Crick. Using theory of change to design and evaluate public health interventions: a systematic review.

Implementation Science, v. 11, n. 63, mai., 2016.

CIENTISTA BETA. Quem somos, 2020a. Disponível em:

https://cientistabeta.com.br/quem-somos/ Acesso em: 14 fev. 2020.

CIENTISTA BETA. Nossas iniciativas. 2020b. Disponível em: https://cientistabeta.com.br Acesso em: 14 fev. 2020.

CHEN, Huey-Tsyh. Theory-driven evaluation: Conceptual framework, application and advancement. In: STROBL Rainer; LOBERMEIER Olaf; HEITMEYER Wilhelm (Eds) Evaluation von Programmen und Projekten für eine demokratische Kultur. Wiesbaden: Springer VS, 2012.

CRUZ FILHO, Paulo Roberto Araújo. Avaliação e mensuração de impacto. In: ANASTÁCIO, Mari Regina; CRUZ FILHO, Paulo Roberto Araújo, Cruz; MARTINS, James (Org.). Empreendedorismo social e inovação social no contexto brasileiro. Curitiba: PUCPRESS / Editora Universitária Champagnat, 2018. p. 31-50.

FABIANI, Paula; VICENTE, Francisco José; MOSANER, Marcelo; CAMELO, Rafael; REBEHY, Sofia. Avaliação de Impacto Social metodologias e reflexões. São Paulo: IDIS, 2018.

GASPARINI, Max Felipe Vianna; FURTADO, Juarez Pereira. Avaliação de Programas e Serviços Sociais no Brasil: uma análise das práticas no contexto atual. Serviço Social \& Sociedade, São Paulo, n. 117, p. 122-141, 2014.

IDIS - Instituto pelo Desenvolvimento do Investimento Social. Amigos do Bem, Parceiros da Educação e Gerando Falcões contratam IDIS para avaliação de impacto SROI, 2020. Disponível em:

https://www.idis.org.br/amigos-do-bem-parceiros-da-educacao-e-gerando- 
falcoes-contratam-idis-para-avaliacao-de-impacto-sroi/ Acesso em: 07 out. 2020.

IDIS- Instituto pelo Desenvolvimento do Investimento Social; CAF - Charities Aids Foundation. Um guia para o retorno social do investimento, 2012. Disponível em: https://idis.org.br/wpcontent/uploads/2016/09/GUIA_SROI_PT_2.pdf Acesso em: 07 out. 2020.

LIMEIRA, Tânia Maria Vidigal. Negócios de impacto social. São Paulo: Saraiva, 2018.

MAYNE, John. Useful Theory of Change Models. Canadian Journal of Program Evaluation, v. 30, n. 2 p. 119-142, 2015.

NAÇÕES UNIDAS BRASIL. Objetivo de Desenvolvimento Sustentável 4. 2020. Disponível em: https://brasil.un.org/pt-br/sdgs/4 Acesso em: 04 out 2020.

OLSEN, Sara; GALIMIDI, Brett. Social venture technology group. Catalog of approaches to impact measurement. Assessing social impact in private ventures. Version 1.1. New York: The Rockefeller Foundation, 2008.

PAULA, Cleberson Luis Santos de; BRASIL, Haroldo Guimarães; MÁRIO, Poueri do Carmo. Mensuração do Retorno Social de Organizações sem Fins Lucrativos por meio do SROI - Social Retorno On Investiment. Revista Contabilidade Vista e Revista, v. 20, n.3, p. 127-155, 2009. Disponível em:

https://revistas.face.ufmg.br/index.php/contabilidadevistaerevista/article/view /654/611 Acesso em: 12 nov 2020.

MURAD, Elisa Pereira. Desenvolvimento de métricas para avaliação dos impactos relacionados às ações da Organização não Governamental Amigos de Itajubá. 2017. Dissertação (Mestrado Profissional) - Universidade Federal de Itajubá, Itajubá, 2017.

RIBEIRO, Gilberto. O que o futuro reserva para a avaliação de impacto? In: Relatório: Avanços, conquistas e orientações para o futuro. Mensagem da Força Tarefa. 2017. Disponível em: https://aliancapeloimpacto.org.br/wpcontent/uploads/2020/02/alianca-avancos-conquistas-orientacoes-web.pdf Acesso em: 15 out. 2020.

SILVA Amalin Vieira da. Como empreendedores sociais constroem e mantêm a sustentabilidade de seus empreendimentos. Rio de Janeiro: Fundação Getúlio Vargas, 2009.

SUGAHARA, Cibele Roberta; RODRIGUES, Patrícia Peres. Avaliação de impacto de negócios sociais e teoria da mudança. Revista Nacional de

Gerenciamento de Cidades, v. 7, n. 46, 2019. 
VELDMAN, Paul. Learning Social Metrics from International

Development. Columbia University. 2009. Disponível em:

https://www.frbsf.org/community-development/files/Veldman.pdf Acesso em:

27 out. 2019.

WILLIAMS, Andrew; MORRIS, John Charles. The Development of TheoryDriven Evaluation in the Military: Theory on the Front Line. American Journal of Evaluation, v. 30. n. 1, p. 62-79, 2009. 